\title{
MOTIVASI ANAK DALAM PEMELIHARAAN KESEHATAN GIGI TERHADAP STATUS KESEHATAN GIGI PADA SISWA/I KELAS III-A SD SWASTA CERDAS BANGSA JL. TITI KUNING NAMORAMBE LINGK. VI SIDOREJO DELI TUA TAHUN 2014
}

\author{
Rosdiana T. Simaremare, Asnita Bungaria Simaremare \\ Jurusan Keperawatan Gigi Poltekkes Kemenkes Medan
}

\begin{abstract}
Abstrak
Motivasi kesehatan adalah segala dorongan atau keinginan seseorang, baik yang dapat diamati secara langsung maupun yang tidak dapat diamati secara langsung, yang berkaitan dengan pemeliharaan dan upaya peningkatan kesehatan. Tujuan penelitian ini untuk mengetahui gambaran motivasi anak dalam pemeliharaan kesehatan gigi terhadap status kesehatan gigi pada siswa/i kelas III-A SD Swasta Cerdas Bangsa J1. Titi Kuning Namorambe Lingk. VI Sidorejo Deli Tua. Jenis penelitian yang dilakukan adalah penelitian deskriptif. Cara pengumpulan data dilakukan dengan memberikan kuisioner pada siswa yang berjumlah 38 orang untuk mengetahui gambaran motivasi siswa dalam pemeliharaan kesehatan gigi terhadap status def-t, DMF-T dan OHIS. Berdasarkan penelitian yang dilakukan diperoleh hasil sebagai berikut : tingkat motivasi siswa kelas III-A SD Swasta Cerdas Bangsa Jl. Titi Kuning Namorambe Lingk. VI Sidorejo Deli Tua dimana kriteria baik sebanyak 14 siswa (36\%), kriteria sedang sebanyak 22 siswa (57\%) dan kriteria buruk sebanyak 2 siswa (5\%). Status def-t pada siswa kelasa III-A SD Swasta Cerdas Bangsa Jl. Titi Kuning Namorambe Lingk. VI Sidorejo Deli Tua cenderung cukup tinggi dimana terdapat status angka def-t dengan rata-rata 4,52. Status DMF-T cenderung rendah dimana terdapat angka status DMF-T dengan ratarata 1, sedangkan status OHIS cenderung sedang dimana angka status OHIS 1,51.
\end{abstract}

Kata kunci : Pengetahuan dan tindakan mahasiswa, alat-alat pencabutan gigi

\section{PENDAHULUAN}

\section{Latar Belakang}

Undang-undang kesehatan No. 36 tahun 2009 tentang kesehatan, bahwa tujuan pembangunan kesehatan adalah meningkatkan kesadaran, kemauan dan kemampuan hidup sehat bagi setiap orang agar terwujud derajat kesehatan masyarakat yang setinggitingginya. Untuk mewujudkan derajat kesehatan yang setinggi-tingginya bagi masyarakat, diselenggarakan upaya kesehatan yang terpadu dan menyuluruh dalam bentuk upaya kesehatan perorangan dan upaya kesehatan masyarakat.

Timbulnya masalah kesehatan gigi dan mulut pada masyarakat salah satunya adalah karena mengabaikan kesehatan gigi dan mulut. Hal tersebut dilandasi oleh kurangnya motivasi akan pentingnya pemeliharaan kesehatan gigi dan mulut.

Peningkatan kesehatan dalam kesehatan gigi dan mulut dapat dilakukan dengan memberikan motivasi. Motivasi dilakukan untuk menunjang tercapainya hidup sehat. Motivasi kesehatan merupakan dorongan yang dilakukan dengan menanamkan keyakinan, sehingga masyarakat tidak hanya sadar, tahu dan mengerti, tetapi juga mau dan bisa melakukan suatu anjuran yang ada hubungannya dengan kesehatan.
Motivasi yang berasal dari dalam diri seseorang dapat disebabkan seseorang mempunyai keinginan untuk dapat menggapai sesuatu yang diharapkannya. Motivasi anak dalam pemeliharaan kesehatan gigi dapat dilakukan dengan menyikat gigi yang baik dan benar, sehingga selain untuk menjaga kebersihan gigi juga dapat mencegah terjadinya karies gigi.

Pemeliharaan kesehatan gigi ini dapat dilakukan sejak dini pada anak sekolah dasar, agar anak termotivasi untuk meningkatkan kebersihan dan kesehatan giginya.

Berdasarkan latar belakang tersebut di atas, penulis tertarik melakukan penelitian pada Siswa/I kelas III-A SD Swasta Cerdas Bangsa. Adapun tujuan penelitian ini adalah untuk memperoleh bagaimana Gambaran Motivasi Anak Dalam Pemeliharaan Kesehatan Gigi Terhadap Status Kesehatan Gigi pada Siswa/I Kelas III-A SD Swasta Cerdas Bangsa Jl. Titi Kuning Namorambe Lingk. VI Sidorejo Deli Tua.

\section{Perumusan Masalah}

Berdasarkan latar belakang yang telah diuraiankan di atas, penulis ingin mengetahui bagaimana "Gambaran Motivasi Anak Dalam Pemeliharaan Kesehatan Gigi Terhadap Status Kesehatan Gigi” pada Siswa/I Kelas III-A SD Swasta Cerdas Bangsa Jl. Titi Kuning Namorambe Lingk. VI Sidorejo Deli Tua. 


\section{Tujuan Umum}

Penelitian ini dilakukan bertujuan untuk mengetahui Gambaran Motivasi Anak Dalam Pemeliharaan Kesehatan Gigi Terhadap Status Kesehatan Gigi pada Siswa/I Kelas III-A SD Swasta Cerdas Bangsa Jl. Titi Kuning Namorambe Lingk. VI Sidorejo Deli Tua.

\section{Tujuan Khusus}

1. Untuk mengetahui motivasi anak terhadap pemeliharaan kesehatan gigi dan mulut pada siswa/i kelas III-A SD Swasta Cerdas Bangsa Jl. Titi Kuning Namorambe Lingk. VI Sidorejo Deli Tua.

2. Untuk mengetahui motivasi anak terhadap status kebersihan gigi (OHI-S) pada siswa/i kelas III-A SD Swasta Cerdas Bangsa Jl. Titi Kuning Namorambe Lingk. VI Sidorejo Deli Tua.

3. Untuk mengetahui motivasi anak terhadap status kesehatan gigi susu (def-t) dan status kesehatan gigi permanen (DMF-T) pada siswa/i kelas III-A SD Swasta Cerdas Bangsa Jl. Titi Kuning Namorambe Lingk. VI Sidorejo Deli Tua.

\section{Manfaat Penelitian}

Data yang diperoleh dari penelitian diharapkan dapat digunakan :

1. Sebagai masukan atau informasi bagi siswa/i kelas III-A SD Swasta Cerdas Bangsa Jl. Titi Kuning Namorambe Lingk. VI Sidorejo Deli Tua.

2. Menjadi masukan bagi pihak sekolah dalam melaksanakan program Upaya Kesehatan Gigi Sekolah.

3. Sebagai bahan dan masukan bagi peneliti selanjutnya.

\section{Jenis Dan Desain Penelitian}

Jenis penelitian yang dilakukan adalah penelitian deskriptif dengan metode survey dimana penelitian ini bertujuan untuk mengetahui bagaimana Gambaran Motivasi Anak Terhadap Pemeliharaan Kesehatan Gigi dan Mulut pada siswa/i kelas III-A SD Swasta Cerdas Bangsa Jl. Titi Kuning Namorambe Lingk. VI Sidorejo Deli Tua.

\section{Lokasi Penelitian}

Penelitian ini dilakukan di SD Swasta Cerdas Bangsa Jl. Titi Kuning Namorambe Lingk. VI Sidorejo Deli Tua.

\section{Waktu Penelitian}

Penelitian ini dilakukan pada bulan September sampai dengan Oktober 2014.

\section{Populasi Penelitian}

Populasi adalah keseluruhan subjek penelitian (Arikunto, 2002). Populasi dalam penelitian ini adalah siswa/i kelas III-A SD Swasta Cerdas Bangsa Jl. Titi Kuning Namorambe Lingk. VI Sidorejo Deli Tua yang berjumlah 38 orang.

\section{Sampel Penelitian}

Sampel adalah sebagian dari jumlah populasi yang diteliti. Apabila subjek kurang dari 100 maka lebih baik diambil semua sehingga penelitiannya merupakan penelitian populasi (Arikunto, 2002). Maka dari itu, sampel diambil dari total populasi siswa/i kelas III-A SD Swasta Cerdas Bangsa Jl. Titi Kuning Namorambe Lingk. VI Sidorejo Deli Tua yang berjumlah 38 orang.

\section{Jenis dan Cara Pengumpulan Data}

Jenis data yang dikumpulkan adalah data primer yang dilakukan dengan menggunakan kuisioner dan pemeriksaan secara langsung. Data langsung diambil oleh peneliti dan tim ke lokasi penelitian di SD Swasta Cerdas Bangsa Jl. Titi Kuning Namorambe Lingk. VI Sidorejo Deli Tua yang terdiri dari dua orang.

1. Orang pertama bertugas untuk memberikan kuisioner. Kuisioner terdiri dari 10 pertanyaan tentang motivasi pemeliharaan kesehatan gigi dan mulut. Mengambil kembali hasil kuisioner yang telah dijawab, juga memeriksa kebersihan gigi dan mulut siswa.

2. Orang kedua bertugas untuk memanggil siswa satu persatu berdasarkan nomor urut pada absensi dan mencatat hasil pemeriksaan.

Kuisioner yang terdiri dari 10 pertanyaan masingmasing bagian dibagi dalam 3 kategori penilain yaitu kategori baik, sedang, buruk. Sehingga didapat skor dengan rentang tiga setiap kategori sebagai berikut :

Skor 8-10 : kategori baik

Skor 4-7 : kategori sedang

Skor $0-3$ : kategori buruk

Selanjutnya dilakukan pengumpulan data status kesehatan gigi dengan melakukan pemeriksaan gigi responden (siswa/i) untuk mengetahui indeks karies gigi susu (def-t) dan indeks karies gigi permanen (DMF-T) serta status kebersihan gigi (OHI-S). Dalam pemeriksaan gigi ini digunakan alat dan bahan yaitu :

1. Alat yang terdiri dari :

- Kaca mulut

- Sonde

- Pinset

- Nier bekken

- Excavator

- Handuk steril

- Format pemeriksaan gigi geligi

- Lembaran kuisioner

2. Bahan terdiri dari :

- Kapas

- Sabun cair detol

Setiap siswa/I diperiksa giginya dan hasil pemeriksaan dicatat pada format pemeriksaan status gigi geligi. Hasil pemeriksaan dikumpulkan dan dimasukkan ke dalam tabel distribusi frekuensi. Sebelum melakukan pemeriksaan peneliti menjelaskan maksud dan tujuan penelitian kepada responden. 


\section{Pengolahan dan Analisa Data}

Setelah data dikumpulkan dan kuisioner dikelompokkan berdasarkan pertanyaan tentang motivasi anak terhadap pemeliharaan kesehatan gigi dan mulut ke dalam tabel distribusi frekuensi. Pemeriksaan status kesehatan gigi dibagi dalam tiga bagian yaitu OHIS, indeks karies gigi susu (def-t) dan indeks karies gigi permanen (DMF-T) yang dimasukkan ke dalam tabel distribusi frekuensi. Pengolahan data meliputi 3 langkah, yaitu :

1. Editing (Memeriksa)

Hal ini dilakukan setelah semua data yang dikumpulkan melalui pemeriksaan langsung terhadap anak-anak. Kegiatan yang dilakukan adalah mengecek kelengkapan data kuisioner dan status kesehatan gigi.

2. Coding (Pengkodean)

Memberikan tanda terhadap pemeriksaan OHI-S dan karies gigi yang telah dilakukan terhadap anak-anak. Hal ini dimaksudkan untuk mempermudah waktu mengadakan tebulasi data dan analisa data.

3. Tabulasi Data

Pekerjaan tabulasi data dilakukan, jika semua masalah editing dan koding sudah selesai. Artinya sudah tidak ada lagi permasalahan yang timbul dalam editing dan koding. Sehingga data dapat dimasukkan ke dalam tabel frekuensi.

\section{Hasil Penelitian}

Hasil penelitian motivasi anak dalam pemeliharaan kesehatan gigi terhadap status kesehatan gigi pada siswa/i kelas III-A SD Swasta Cerdas Bangsa Jl. Titi Kuning Namorambe Lingk. VI Sidorejo Deli Tua disajikan dalam bentuk tabel distribusi frekuensi sebagai berikut.

Tabel A.1.

Distribusi Frekuensi Motivasi Anak Dalam Pemeliharaan Kesehatan Gigi Terhadap Status Kesehatan Gigi Pada Siswa/I Kelas III-A SD Swasta Cerdas Bangsa Jl. Titi Kuning Namorambe Lingk. VI Sidorejo Deli Tua

\begin{tabular}{cccc}
\hline No & Kriteria Motivasi & Sampel (n) & Persentase \\
\hline 1 & Baik & 14 & $36 \%$ \\
2 & Sedang & 22 & $57 \%$ \\
3 & Buruk & 2 & $5 \%$ \\
\hline & Jumlah & 38 & $100 \%$ \\
\hline
\end{tabular}

Dari tabel di atas dapat diketahui bahwa responden yang memiliki motivasi dalam pemeliharaan kesehatan gigi dengan kriteria baik sebanyak 14 orang (36\%), kriteria sedang sebanyak 22 orang $(57 \%)$ dan kriteria buruk sebanyak 2 orang (5\%).

Tabel A.2.

Distribusi Frekuensi Motivasi Anak Dalam Pemeliharaan Kesehatan Gigi Terhadap Status Kebersihan Gigi Pada Siswa/I Kelas III-A SD Swasta Cerdas Bangsa Jl. Titi Kuning Namorambe Lingk. VI Sidorejo Deli Tua

\begin{tabular}{cccccc}
\hline $\begin{array}{c}\text { Status } \\
\text { Kebersihan }\end{array}$ & DI & CI & OHIS & $\begin{array}{c}\text { Jumlah } \\
\text { Siswa }\end{array}$ & $\begin{array}{c}\text { Rata- } \\
\text { Rata }\end{array}$ \\
\cline { 2 - 6 } Gigi (OHIS) & 39,5 & 17,9 & 57,4 & 38 & 1,51 \\
\hline
\end{tabular}

Dari tabel di atas dapat diketahui bahwa angka OHI-S siswa/i kelas III-A SD Swasta Cerdas Bangsa Jl. Titi Kuning Namorambe Lingk. VI Sidorejo Deli Tua adalah 57,4 dengan rata-rata 1,51.

Tabel A.3.

Distribusi Frekuensi Motivasi Anak Dalam Pemeliharaan Kesehatan Gigi Terhadap Status Kesehatan Gigi Pada Siswa/I Kelas III-A SD Swasta Cerdas Bangsa Jl. Titi Kuning Namorambe Lingk. VI Sidorejo Deli Tua

\begin{tabular}{ccccccc}
\hline $\begin{array}{c}\text { Status } \\
\text { Kesehatan Gigi } \\
\text { Susu(def-T) }\end{array}$ & d & e & f & def-t & $\begin{array}{c}\text { Jumlah } \\
\text { Siswa }\end{array}$ & $\begin{array}{c}\text { Rata- } \\
\text { rata }\end{array}$ \\
\cline { 2 - 5 } & 136 & 36 & 0 & 172 & 38 & 4,52 \\
\hline $\begin{array}{c}\text { Status } \\
\text { Kesehatan Gigi } \\
\text { Permanen } \\
\text { (DMF-T) }\end{array}$ & D & M & F & DMF-T & & \\
\hline
\end{tabular}

Dari tabel di atas dapat diketahui bahwa status angka def-t siswa/i kelas III-A SD Swasta Cerdas Bangsa Jl. Titi Kuning Namorambe Lingk. VI Sidorejo Deli Tua adalah 172 dengan rata-rata 4,52. Sedangkan status angka DMF-T siswa kelas III-A SD Swasta Cerdas Bangsa Jl. Titi Kuning Namorambe Lingk. VI Sidorejo Deli Tua adalah 38 dengan rata-rata 1 .

\section{Pembahasan}

Berdasarkan hasil penelitian tentang motivasi anak dalam pemeliharaan kesehatan gigi terhadap status kesehatan gigi pada siswa/i kelas III-A SD Swasta Cerdas Bangsa Jl. Titi Kuning Namorambe Lingk. VI Sidorejo Deli Tua, maka dari 38 responden diperoleh 14 orang $(36 \%)$ dengan kriteria baik, 22 orang (57\%) dengan kriteria sedang dan 2 orang (5\%) dengan kriteria buruk.

Motivasi anak dengan kategori sedang terlihat lebih banyak yaitu 22 orang (57\%), ini menunjukkan bahwa belum semua siswa mempunyai motivasi dalam pemeliharaan kesehatan giginya. Menurut Prawira (2012) motivasi pada dasarnya adalah suatu usaha untuk meningkatkan kegiatan dalam mencapai suatu tujuan tertentu, termasuk di dalamnya bagian belajar.

Berdasarkan tabel di atas pemeriksaan gigi yang dilakukan pada siswa/i kelas III-A SD Swasta Cerdas Bangsa Jl. Titi Kuning Namorambe Lingk. VI Sidorejo Deli Tua diketahui bahwa angka OHI-S adalah 57,4 dengan rata-rata 1,51. Menurut Green dan Vermillioon dalam penilaian $\mathrm{OHI}-\mathrm{S}$ ini termasuk dalam kriteria sedang.

Berdasarkan hasil yang diperoleh terlihat bahwa sebagian besar siswa/i mengalami kebersihan gigi (OHI-S) kriteria sedang. Hal ini disebabkan karena belum seluruhnya siswa mempunyai kesadaran akan kebersihan giginya. Anak cenderung menyukai makanan lunak dan manis apalagi orang tua tidak mengarahkan pada jenis makanan yang lebih beragam dan bergizi. Orang tua memegang peranan di dalam menerapkan disiplin dalam melaksanakan tanggung jawab akan kebersihan gigi anak. Oleh karena itu anak lebih dapat diajarkan cara memelihara kesehatan gigi dan mulut secara lebih dini. 
Berdasarkan tabel di atas diketahui bahwa angka def-t dengan rata-rata 4,52 yang artinya ada 4 sampai 5 gigi yang mengalami karies pada setiap siswa. Hal ini disebabkan karena motivasi siswa masih kurang dalam pemeliharaan kesehatan giginya. Menurut Latipah (2012) seseorang dapat termotivasi oleh faktor intrinsik dan faktor ekstrinsik. Angka karies yang tinggi disebabkan karena seseorang tidak termotivasi/terdorong untuk mengarahkan dan melakukan usaha mempertahankan kesehatan giginya sehingga tidak terjadi karies.

Status angka DMF-T dengan rata-rata 1 ini disebabkankan keadaan gigi siswa/i yang masih bercampur dan baru sebagian gigi permanen yang mulai tumbuh. Kesehatan rongga mulut anak-anak dibawah usia 2 tahun sepenuhnya di bawah pengawasan orang tua. Hingga usia 12 tahun sampai selesainya pergantian gigi susu menjadi permanen, orang tua harus tetap memantau. Menurut Latipah (2012) peranan kelompok dimana individu bergabung dapat membantu individu mendapatkan kebutuhan.

\section{Simpulan}

Berdasarkan hasil penelitian dapat dikemukakan kesimpulan, yaitu :

1. Tingkat motivasi siswa/i kelas III-A SD Swasta Cerdas Bangsa Jl. Titi Kuning Namorambe Lingk. VI Sidorejo Deli Tua dimana kriteria baik sebanyak 14 siswa (36\%), kriteria sedang sebanyak 22 siswa (51\%), sedangkan kriteria buruk sebanyak 2 siswa (5\%) yang dilakukan pada 38 siswa.

2. Status OHIS pada siswa/i kelas III-A SD Swasta Cerdas Bangsa Jl. Titi Kuning Namorambe Lingk. VI Sidorejo Deli Tua cenderung sedang dimana terdapat status angka OHIS rata-rata 1,51.

3. Status def-t pada siswa/i kelas III-A SD Swasta Cerdas Bangsa Jl. Titi Kuning Namorambe Lingk. VI Sidorejo Deli Tua cenderung cukup tinggi dimana terdapat status angka def-t dengan ratarata 4,52 .

4. Status DMF-T pada siswa/i kelas III-A SD Swasta Cerdas Bangsa Jl. Titi Kuning Namorambe Lingk. VI Sidorejo Deli Tua cenderung rendah dimana terdapat status angka DMF-T rata-rata 1.

\section{Saran}

1. Diharapkan kepada siswa/i SD Swasta Cerdas Bangsa Jl. Titi Kuning Namorambe Lingk. VI
Sidorejo Deli Tua dapat melakukan perawatan giginya pada dokter gigi atau tenaga kesehatan gigi (Puskesmas, Klinik Gigi dan Rumah Sakit) secara berkala.

2. Untuk pihak sekolah diharapkan dapat melaksanakan pelayanan kesehatan gigi melalui Usaha Kesehatan Gigi Sekolah (UKGS) yang bekerja sama dengan pihak Puskesmas.

3. Penelitian ini diharapkan dapat menambah wawasan dan pengetahuan bagi peneliti, untuk menerapkan ilmu yang diperoleh serta sebagai masukan kepada peneliti yang lain.

\section{DAFTAR PUSTAKA}

Anggriana, D., 2005. Faktor pendorong motivasi orang tua merawatkan gigi anak di klinik Fakultas Kedokteran Gigi Unair [pdf] Surabaya: Fakultas Kedokteran Gigi Universitas Airlangga <http://duniapsikologi.dagdigdug.com/files/2006/ 12/konsep-diri.pdf $>$ [diakses Des 2006]

Arikunto, S., 2002, Prosedur Penelitian, Rineka Cipta.Jakarta

Asmani, J.M., 2012. Kiat Mengatasi Kenakalan Remaja di sekolah, Jogjakarta.Buku Biru

Boedihardjo, 1985, Pemeliharaan Kesehatan Gigi Keluarga, Airlangga University press. Surabaya

Eka, I.N., 2007. Pengaruh Pendidikan Kesehatan Gigi Terhadap Pengetahuan dan Sikap Anak Usia Sekolah di SD Boto Kembang Kulonprogo [pdf] yokyakarta: Fakultas Ilmu Kesehatan, Universitas Pekalongan <http://www.psychologymania.com/2008/08/pen gertian-dukungan-keluarga.html $>$ [diakses agustus 2008]

Latipah, E., 2012. Pengantar Psikologi Pendidikan, Pedagogia. Yokyakarta

Prawira, P.A., 2012. Psikologi Pendidikan Dalam Perspektif Baru, Ar-Ruzz Media. Jogjakarta

Putri, M.H., Eliza, H., Neneng, N., 2010. Ilmu Pencegahan Penyakit Jaringan Keras Dan Jaringan Pendukung Gigi, EGC. Jakarta

Ramadhan, A.G., 2010. Serba-Serbi Kesehatan Gigi dan Mulut, Bukune. Jakarta. 